\title{
Evaluation of the Seismic Response Parameters for Infilled Reinforced Concrete Frame Buildings
}

\author{
Dina Hesham Mohamed Helmy ${ }^{1}$, Hussein Okail ${ }^{2}$, Mostafa Zidan ${ }^{3}$ \\ ${ }^{I}$ Graduate Researcher, Structural Engineering Department, Faculty of Engineering, Ain Shams University, \\ Cairo, Egypt \\ ${ }^{2}$ Associate Professor of structural engineering, Structural Engineering Department, Faculty of Engineering, Ain \\ Shams University, Cairo, Egypt \\ ${ }^{3}$ Professor of structural engineering, Structural Engineering Department, Faculty of Engineering and \\ Technology, Future University, Cairo, Egypt
}

\begin{abstract}
RC frames with unreinforced masonry infill walls are a common form of construction all around the world. Often, engineers do not consider masonry infill walls in the design process because the final distribution of these elements may be unknown to them, or because masonry walls are regarded as non-structural elements. Separation between masonry walls and frames is often not provided and, as a consequence, walls and frames interact during strong ground motion. This leads to structural response deviating radically from what is expected in the design. The presence of masonry infills can result in higher stiffness and strength and it is cheap and built with low cost labor. Under lateral load, Masonry walls act as diagonal struts subjected to compression, while reinforced concrete confining members (Frames) act in tension and/or compression, depending on the direction of lateral earthquake forces. The main objective of this research is to develop a realistic matrix for the response modification factors for medium-rise skeletal buildings with masonry infills. In this study, the contribution of the masonry infill walls to the lateral behavior of reinforced concrete buildings was investigated. For this purpose, a five, seven and ten stories buildings are modelled as bare and infilled frames. The parameters investigated were infill ratio, panel aspect ratio, unidirectional eccentricity, bidirectional eccentricities. A Parametric study was developed on the behavior of medium rise infilled frame buildings under lateral loads to investigate the effect of these parameters as well as infill properties on this behavior.
\end{abstract}

Keywords: Diagonal struts, Infill, Masonry, Response modification.

\section{Introduction}

Infilled reinforced concrete (RC) frames are reinforced concrete frames with unreinforced masonry infill walls. These structures are amongst the most common structural forms for low to medium-rise buildings in the world. For infilled frame buildings, infill panels are used as partitions, whereas the bounding frame is designed as a structural skeleton to withstand gravity and lateral loading. Masonry structural walls are usually used by architects for its aesthetic qualities but it also contributes in resisting lateral loads such as wind loads and seismic loads. Design engineers consider infills as non-structural components and neglect its influence on the overall structural performance. Thus, the actual performance of infilled RC frames will differ from the expected performance based on the structural analyses. However, the structural behavior of infilled frames and bare frames structures differ because the presence of infills, regularly and irregularly arranged infills, can significantly alter local stress distributions in the adjacent frame members and vary the overall structural dynamic behavior. Furthermore, the brittle nature of masonry infill materials often imposes more harm on the hysteretic behavior of structures and causes severe localized damage in the adjacent braced structural members under reversed cyclic loading. Consequently design engineers should consider the effect of infills on the overall structural performance in their analyses. This research presents an analytical program conducted to assess the structural performance of infilled reinforced concrete frames buildings with different configurations under lateral loads and study their dynamic response. Also the seismic response modification factors will be evaluated for those buildings according to FEMA 695 [1]. And a realistic response modification factors matrix will be proposed for medium-rise infilled frames buildings.

\subsection{Load Transfer Mechanism}

Infills contribute in the resistance of the lateral deformations of the RC frame; it acts as a diagonal compression strut. Thus, infills add lateral stiffness to the building. The structural load transfer mechanism is changed from frame action to truss action as shown in Fig.1; the columns of the frame now bear increased axial forces but with reduced bending moments and shear forces. 


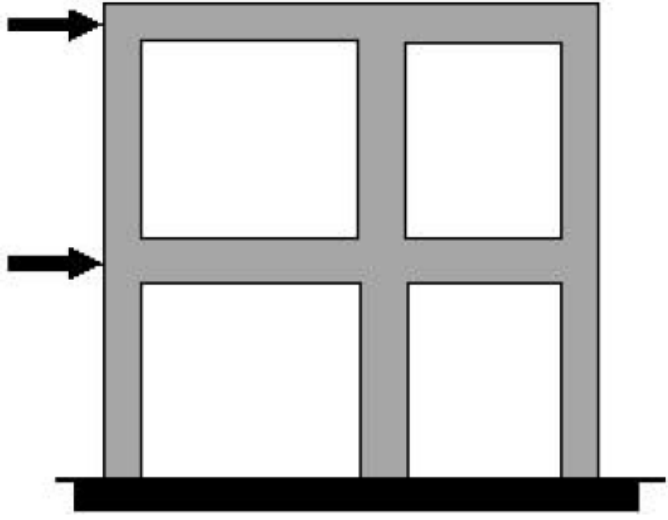

(a) Frame action in bare

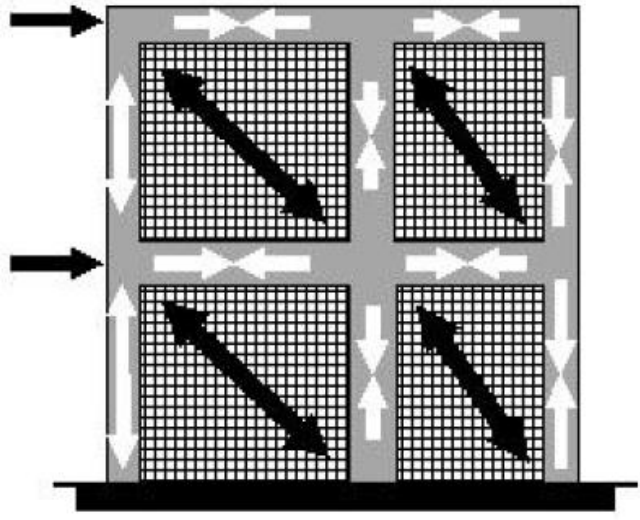

(b) Truss action in infilled frame

Fig.1 - Change in the lateral load transfer mechanism due to the masonry infill walls interference [2].

When infills are irregularly placed in plan or in elevation of the building, a structural load transfer mechanism with both frame action and truss action, may develop. In such structures, the following effects may happen; the soft-story effect that happens when a story has relatively lesser infills than the adjacent stories, the short-column effect that happens when infills are raised up to a partial height of the columns, and the torsional effect that happens when infills are unsymmetrically distributed in plan; all these effects can cause excessive ductility demands on frame columns and significantly change the collapse mechanism. Even when the infills are structurally separated from the RC frame, with some lateral displacement, the frame may come in contact with the infills and increase the stiffness of the building [2].

\subsection{Modes of Failure of infilled frames}

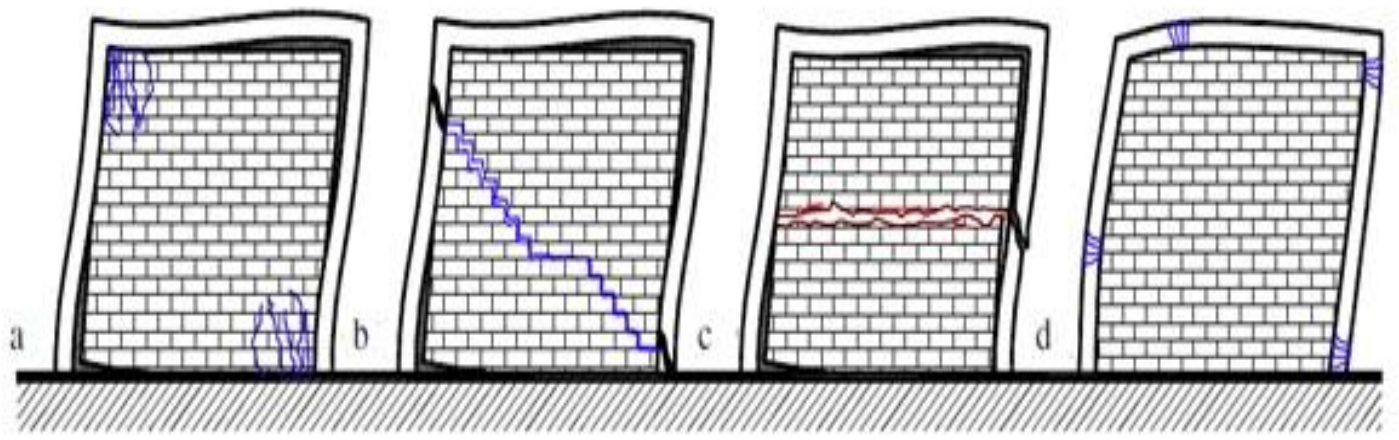

Fig.2 - In-plane collapse modes. (a) Corner Crushing mode, (b) Diagonal cracking mode, (c) Sliding Shear mode, and (d) Frame Failure mode [3].

Fig.2 illustrates the different modes of failure of infilled frames. The crushing of corners mode as shown in Fig.2a is associated with the crushing of the infill in at least one of its laterally loaded corners. This mode generally occurs in case of weak masonry infill panel surrounded by a frame with weak joints and strong members. The compression diagonal cracking mode corresponds to a shear diagonal collapse and characterized by cracking along the diagonal of the infill as shown in Fig.2b and this is a common mechanism that is often accompanied by a damage within the frame. The sliding shear mode is related to the sliding shear failure through bed joints, this mechanism generally happens in the case of infill with weak mortar joints surrounded by a strong frame as shown in Fig.2c. The failure of the frame mode appears in the form of a distributed plastic hinges throughout the frame as shown in Fig.2d, this failure mechanism happens when the frame is weak and the infill is strong [3].

\subsection{Seismic Response Parameters}

FEMA P695 [1] defined seismic performance parameters in terms of the global inelastic response (idealized pushover curve) of the seismic-force-resisting system as shown in Fig.3. The term $\mathrm{V}_{\mathrm{E}}$ represents the force level that would be developed in the seismic-force-resisting system if the system remains entirely linearly elastic during earthquake ground motions. The term $\mathrm{V}_{\max }$ represents the actual maximum strength of the fullyyielded system, while the term $\mathrm{V}$ is the seismic base shear required for design. 

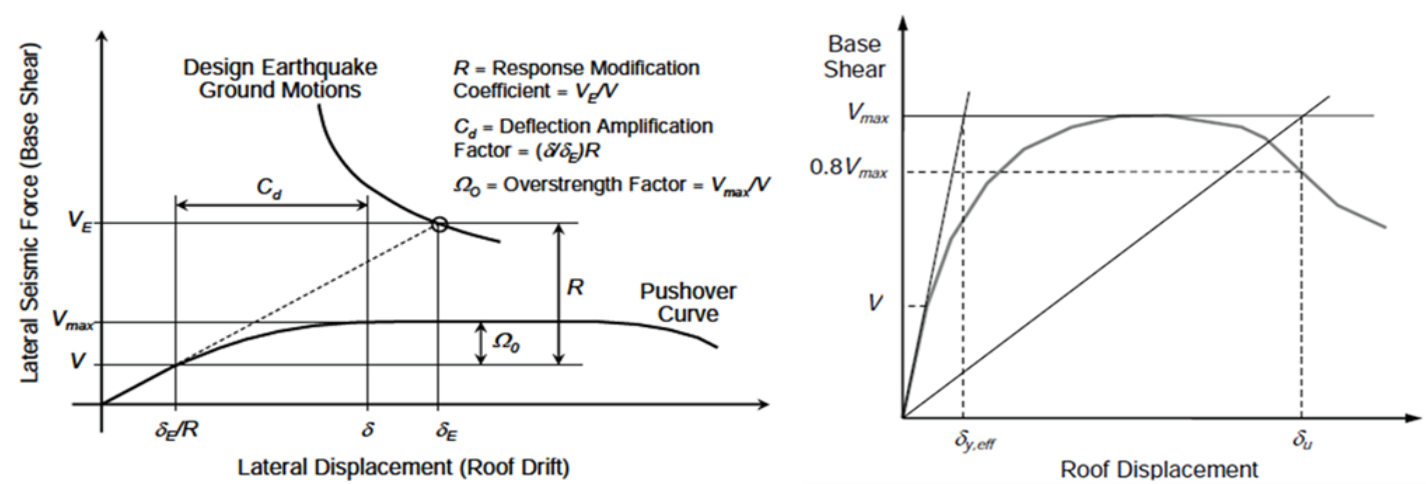

Fig.3 - Illustration of seismic performance parameters $\left(\mathrm{R}, \Omega_{\mathrm{o}}\right.$, and $\mathrm{Cd}$ ) as defined in the Commentary to the NEHRP Recommended Provisions [1].

The $\mathrm{R}$ parameter is the response modification coefficient and is given by:

$\mathrm{R}=\frac{V_{E}}{V}$

And the $\Omega_{\mathrm{o}}$ parameter is the over strength factor and is given by:

$\Omega_{\mathrm{o}}=\frac{V_{\max }}{V}$

The term $\delta_{\mathrm{E}}$ represents the roof drift of the seismic-force resisting system corresponding to design base shear, $\mathrm{V}_{\mathrm{E}}$, assuming that the system remains essentially elastic for this level of force, and the term $\delta$ represents the assumed roof drift of the yielded system corresponding to the maximum strength of the fully-yielded system $\mathrm{V}_{\max }$. As illustrated in the figure and defined by Equation 3, the $\mathrm{C}_{\mathrm{d}}$ parameter is the deflection amplification factor and is given by:

$\mathrm{C}_{\mathrm{d}}=\frac{\delta}{\delta_{E}} \mathrm{R}$

A nonlinear static pushover analysis is used to quantify the maximum base shear capacity $\mathrm{V}_{\max }$ and the ultimate displacement $\delta_{\mathrm{u}}$, which are then used to compute overstrength, $\Omega$ and period-based ductility, $\mu_{\mathrm{T}}$. In order to quantify these values, the lateral loads are applied monotonically until a loss of $20 \%$ of the base shear capacity $(0.8 \mathrm{Vmax})$ is achieved. The idealized pushover curve define the maximum base shear capacity $\mathrm{V}_{\max }$ and the ultimate displacement $\delta_{\mathrm{u}} \cdot \mathrm{V}_{\max }$ is taken as the maximum base shear strength at any point on the pushover curve, and $\delta_{u}$ is taken as the roof displacement at the point of $20 \%$ strength loss $\left(0.8 \mathrm{~V}_{\max }\right)$ [1].

\subsubsection{Response modification factor for infilled frames}

Based on the assumption for the idealized yield displacement and the definition of the ultimate displacement, a wide range of response modification factors may be achieved while the different codes such as standard building code [7], Uniform Building code [8], ASCE (American Society of Civil Engineering) [9] and Egyptian code [11] specify the ductility factor as absolute value for each type of systems as shown in Table 1.

Table 1. The Ductility factor values specified in different codes

\begin{tabular}{|c|l|c|}
\hline Code & \multicolumn{1}{|c|}{ Seismic force-resisting system } & Response Modification Coefficient, $\mathbf{R}$ \\
\hline \multirow{4}{*}{$\begin{array}{c}\text { ASCE 7- } \\
05\end{array}$} & Special reinforced concrete moment & 8 \\
\cline { 2 - 3 } & Intermediate reinforced concrete & 5 \\
\cline { 2 - 3 } & Ordinary reinforced concrete moment & 3 \\
\hline \multirow{2}{*}{$\begin{array}{c}\text { Uniform } \\
\text { Building } \\
\text { Code 97 }\end{array}$} & Concrete special moment-resisting frame (SMRF) & 8.5 \\
\cline { 2 - 3 } & Concrete intermediate moment-resisting frame (IMRF) & 5.5 \\
\cline { 2 - 3 } & Concrete ordinary moment-resisting frame (OMRF) & 3.5 \\
\hline SBC & Special reinforced concrete moment frames & 6.5 \\
\cline { 2 - 3 } $301-2007$ & Intermediate reinforced concrete moment frames & 4 \\
\cline { 2 - 3 } & Ordinary reinforced concrete moment frames & 2.5 \\
\hline Egyptian & Ordinary reinforced concrete moment frames & 5 \\
Code & & \\
\hline
\end{tabular}




\section{Analytical program}

Modelling of masonry infill panels requires a detailed description of materials. Masonry is a brittle material that is characterized by special directional properties due to the mortar joints which act as plane of weakness. Several trials in the analysis of infilled frames since Mid-1950 have yielded several analytical models. These analytical models can be classified as macro and micro models depending on their complexity, the detail by which they model an infill wall, and the information they provide concerning the behavior of the structure [4]. A basic characteristic of a macro-model is that it tries to include the overall global behavior of a structural element without modelling all the possible modes of local failure. On the other hand, micro-models model the structural element behavior with great detail trying to consider possible modes of failure. The most commonly used macro model practical approach is the so called 'diagonal strut model'. According to this approach the infilled masonry is represented by a diagonal strut under compression. The first who suggested the possibility of considering the effect of the infill as an equivalent diagonal bracing was Polyakov 1960 [5]. This suggestion was taken up by Holmes 1961 [6], who modelled the infill by an equivalent diagonal strut made of the same material with the same thickness as the infill panel and a width equal to one-third of the infill diagonal length. Many authors suggested alternative proposals for the evaluation of the equivalent strut width. Some of these studies provide analytical expressions, which include the presence of openings in the infill or analyze special layouts such as the case in which infill and frame are not bonded together [3].

\subsection{Outlines of Analytical Program:}

A five-story, seven-story, and ten-story reinforced concrete infilled frames buildings of a plan shown in Fig.4 were modelled using FE program SeismoStruct [12]. Each building was modelled with different infill panels' configurations also a different infill ratio and the different models are shown in Table 2 as well as a bare frame model. A fixed support condition was provided at the base of all columns while beam column joints were rigidly connected and the structural elements (beams and columns) were modelled as inelastic frame elements (infrmDB) which is capable of modelling members of space frames with geometric and material nonlinearities.

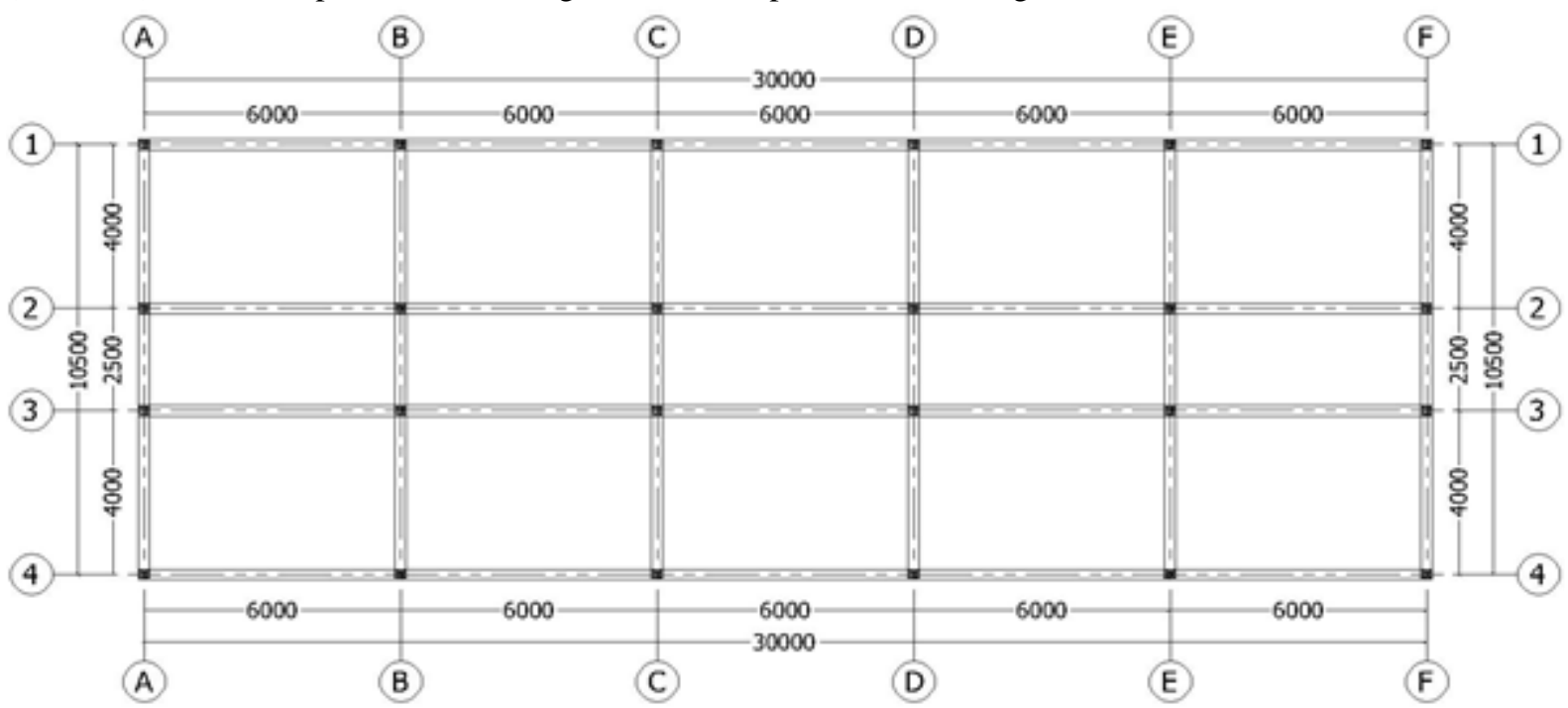

Fig.4 - plan showing the geometry of each floor of the three buildings (all dimensions are in $\mathrm{mm}$ ).

The models that have a symmetrical walls distribution throughout the story with different walls configurations are the control and translational mode buildings while the models that have an unsymmetrical walls distribution throughout the story with different walls configurations are the torsional mode buildings. Table 2 illustrates the distribution of masonry infill walls throughout the typical story of each model (building) with different number of stories. 
Table 2: The different models investigated with the walls distribution throughout the story.

\begin{tabular}{|c|c|c|c|c|c|c|c|c|c|c|c|c|c|}
\hline & & & FF & $\bar{T}$ & $5 A-$ & $\overline{10}$ & & 7 & $\sqrt{7}$ & BL & $\pi$ & & \\
\hline & & & & Y-F & AMES & & & & X-FR & AMES & & & \\
\hline D & $\mathrm{N}$ & & $1-1$ & $2-2$ & $3-3$ & $4-4$ & A-A & B-B & $\mathrm{C}-\mathrm{C}$ & D-D & E-E & F-F & $\mathbf{N}$ \\
\hline 1 & CTRL & $5,7,10$ & FFFFF $^{*}$ & FFFFF & FFFFF & FFFFF & FFF & FEF*: & FEF & FEF & FEF & FFF & CONTROL \\
\hline 2 & T1Y & $5,7,10$ & FFFFF & FFFFF & FFFFF & FFFFF & FFF & EEE & EEE & EEE & EEE & FFF & TRANSLATIONAI \\
\hline 3 & $\mathrm{~T} 2 \mathrm{Y}$ & $5,7,10$ & FFFFF & FFFFF & FFFFF & FFFFF & FFF & FEF & EEE & EEE & FEF & FFF & TRANSLATIONAI \\
\hline 4 & T3Y & $5,7,10$ & FFFFF & FFFFF & FFFFF & FFFFF & FFF & $\mathrm{EEE}$ & FEF & FEF & EEE & FFF & IRANSLATION \\
\hline 5 & E1X & $5,7,10$ & FFFFF & FFFFF & FFFFF & FFFFF & FFF & FEF & FEF & FEF & EEE & FFF & TORSIONAL \\
\hline 6 & E2X & $5,7,10$ & FFFFF & FFFFF & FFFFF & FFFFF & FFF & FEF & FEF & EEE & EEE & FFF & TORSIONAL \\
\hline 7 & E3X & $5,7,10$ & FFFFF & FFFFF & FFFFF & FFFFF & FFF & FEF & EEE & EEE & EEE & FFF & TORSIONAL \\
\hline 8 & T1X & $5,7,10$ & FFFFF & FFEFF & FFEFF & FFFFF & FFF & FEF & FEF & FEF & FEF & FFF & TRANSLATIONAI \\
\hline 9 & $\mathrm{~T} 2 \mathrm{X}$ & $5,7,10$ & FFFFF & FEEEF & FEEF & FFFFF & FFF & FEF & FEF & FEF & FEF & FFF & IRANSLATIONAI \\
\hline 10 & E1XY & $5,7,10$ & FFFFF & FFFFF & FFEFF & FFFFF & FFF & FEF & FEF & EEE & FEF & FFF & TORSIONAL \\
\hline 11 & E2XY & $5,7,10$ & FFFFF & FFFFF & FFEFF & FFFFF & FFF & FEF & FEF & EEE & EEE & FFF & TORSIONAL \\
\hline 12 & E3XY & $5,7,10$ & FFFFF & FFFFF & FEEEF & FFFFF & FFF & FEF & FEF & EEE & FEF & FFF & TORSIONAL \\
\hline 13 & E4XY & $5,7,10$ & FFFFF & FFFFF & FEEEF & FFFFF & FFF & FEF & FEF & EEE & EEE & FFF & TORSIONAL \\
\hline
\end{tabular}

$$
\text { *F: Infilled Panel }
$$

${ }^{* * E}$ : Empty Panel (bare frame)

\subsection{Modeling Methodology:}

SeismoStruct is a Finite Element package for structural analysis, capable of predicting the large displacement behavior of space frames under static or dynamic loadings, taking into account both geometric nonlinearities and material inelasticity. The infill masonry was modelled as a four-node masonry panel element, Each panel is represented by six strut members; each diagonal direction features two parallel struts, of a length $\left(\mathrm{d}_{\mathrm{m}}\right)$ which varies between 3.9 and $6.7 \mathrm{~m}$ for the infill panels have an aspect ratio (length/height) varies from 0.833 to 2 depending on the location of the structural member in the plan as shown in Fig.4, to carry axial loads across two opposite diagonal corners and a third one to carry the shear from the top to the bottom of the panel as shown in Fig.4. This latter strut only acts across the diagonal that is on compression, hence its "activation" depends on the deformation of the panel. The axial load struts use the masonry strut hysteresis model, while the shear strut uses a dedicated bilinear hysteresis rule. See Table 3 and 4.

Table 3. Strut curve parameters

\begin{tabular}{|l|l|}
\hline \multicolumn{1}{|c|}{ Curve properties } & \multicolumn{1}{c|}{ Values } \\
\hline Initial Young modulus $-\mathrm{E}_{\mathrm{m}}$ & $1600000 \mathrm{kPa}$ \\
\hline Compressive strength $-\mathrm{f}_{\mathrm{m}} \theta$ & $1000 \mathrm{kPa}$ \\
\hline Tensile strength $-\mathrm{f}_{\mathrm{t}}$ & $0 \mathrm{kPa}$ \\
\hline Strain at maximum stress $-\varepsilon_{\mathrm{m}}$ & 0.0012 \\
\hline Ultimate strain $-\varepsilon_{\mathrm{u}}$ & 0.024 \\
\hline Closing strain $-\varepsilon_{\mathrm{cl}}$ & 0.004 \\
\hline Strut area reduction strain $-\varepsilon_{1}$ & 0.0006 \\
\hline Residual strut area strain $-\varepsilon_{2}$ & 0.001 \\
\hline Starting unload. stiffness factor $-\gamma_{\mathrm{un}}$ & 1.5 \\
\hline Strain reloading factor $-\alpha_{\mathrm{re}}$ & 0.2 \\
\hline Strain inflection factor $-\alpha_{\mathrm{ch}}$ & 0.7 \\
\hline Complete unloading strain factor $-\beta_{\mathrm{a}}$ & 1.5 \\
\hline Stress inflection factor $-\beta_{\mathrm{ch}}$ & 0.9 \\
\hline Zero stress stiffness factor $-\gamma_{\mathrm{plu}}$ & 1 \\
\hline Reloading stiffness factor $-\gamma_{\mathrm{pre}}$ & 1.5 \\
\hline Plastic unloading stiffness factor $-\mathrm{e}_{\mathrm{x} 1}$ & 3 \\
\hline Repeated cycle strain factor $-\mathrm{e}_{\mathrm{x} 2}$ & 1.4 \\
\hline
\end{tabular}
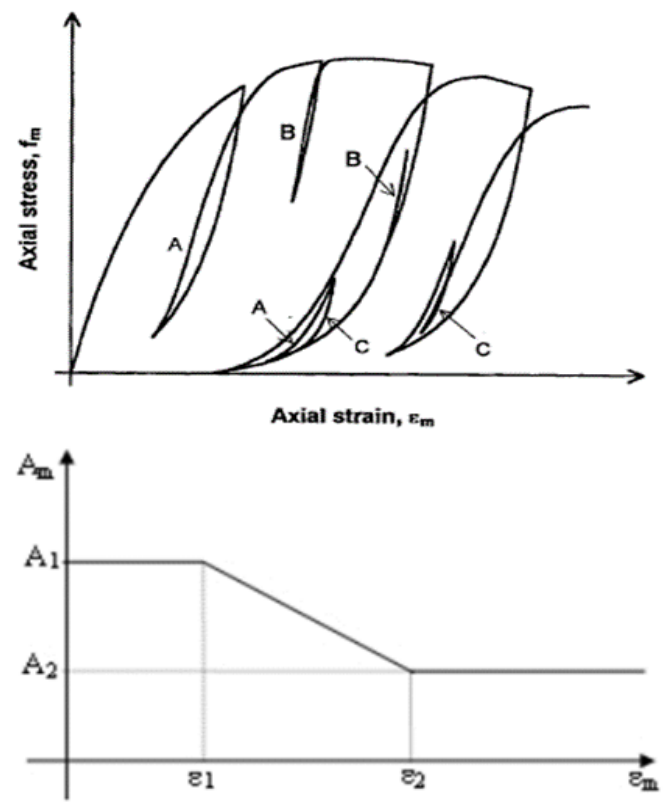
Table 4. Shear Curve Parameters

\begin{tabular}{|l|c|}
\hline \multicolumn{1}{|c|}{ Curve properties } & Values \\
\hline Shear bond strength $-\tau_{\theta}$ & $300 \mathrm{kPa}$ \\
\hline Friction coefficient $-\mu$ & 0.7 \\
\hline Maximum shear strength $-\tau_{\max }$ & $600 \mathrm{kPa}$ \\
\hline Reduction shear factor $-\alpha_{\mathrm{s}}$ & 1.5 \\
\hline
\end{tabular}

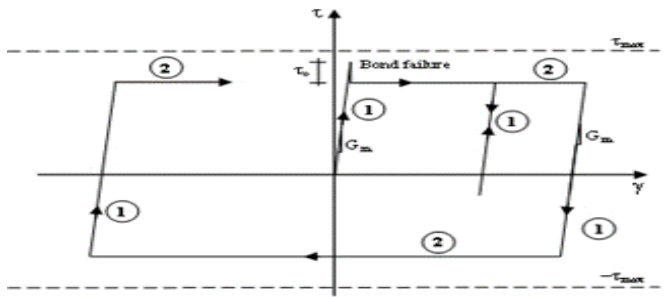

Also as can be observed in Fig.5, four internal nodes are employed to account for the actual points of contact between the frame and the infill panel (i.e. to account for the width and height of the columns and beams, respectively), whilst Four dummy nodes are introduced with the objective of accounting for the contact length between the frame and the infill panel $\left(\mathrm{h}_{\mathrm{z}}\right)$ which introduced as percentage of the vertical height of the panel and was taken $0.87 \mathrm{~m}$. All the internal forces are transformed to the exterior four nodes (which are distant horizontally $\left(\mathrm{X}_{\mathrm{oi}}\right)$ by $2 \%$ of the horizontal side of panel and vertically $\left(\mathrm{Y}_{\mathrm{oi}}\right)$ by $8 \%$ of the vertical side of panel) where the element is connected to the frame. Also the out of plane failure drift introduced as a percentage of the vertical height was taken $5 \%$.

Compression/Tension struts

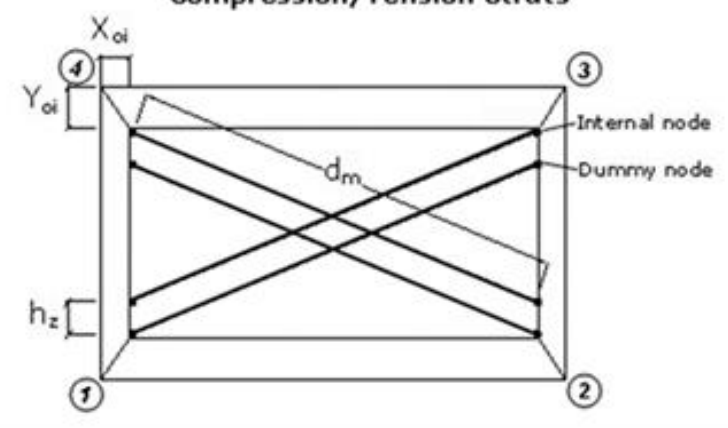

Shear Strut

Fig.5 - Model of infill

For all models ( 5-story, 7-story and 10-story models), the beam section was $250 \mathrm{~mm}$ wide and 500 $\mathrm{mm}$ deep, the slab thickness was $100 \mathrm{~mm}$ and the infill was $250 \mathrm{~mm}$ thick. But the cross section of columns was 250x400 mm, 250x500 mmm, 300x550 mm for 5-story, 7-story and 10-story buildings respectively. Though the masonry infill consists of bricks and mortar, it's modelled as strut members. The compressive strength of concrete was $30 \mathrm{MPa}$ while its tensile strength was $3 \mathrm{MPa}$, and the modulus of elasticity of reinforcement steel was $200 \mathrm{GPa}$ while its yield strength was $360 \mathrm{MPa}$. And the specific weight of masonry was $18 \mathrm{kN} / \mathrm{m}^{3}$ and the structural elements were designed using SAP 2000; the typical floor proposed was modelled and loaded by floor cover loads of $2 \mathrm{kN} / \mathrm{m}^{2}$ and live loads of $3 \mathrm{kN} / \mathrm{m}^{2}$. Therefore the designed reinforcement steel was 3 bars of 12 $\mathrm{mm}$ diameter (lower reinforcement) and 2 bars of $12 \mathrm{~mm}$ diameter (upper reinforcement) for all beams in the different structures mentioned above; and the reinforcement of columns was 4, 6, 8 bars of 18 mm diameter for $5,7,10$-story buildings respectively. The story height in all models was maintained three meters uniformly throughout the story levels.An example of different models are shown in Fig.6.
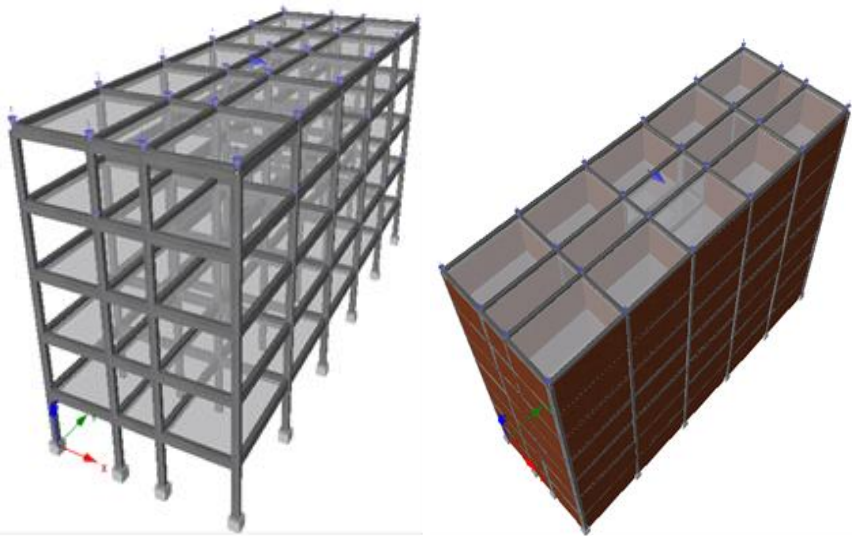

Fig.6 - Example of bare frame and infilled frames FE models 
In addition to permanent gravity actions, each model of building was subjected to an inverted triangle of incremental horizontal loads distributed linearly with the height of building from 0 (at the ground) to $10 \mathrm{kN}$ (at top) in X-direction. A series of incremental static analyses have been conducted on all structures under lateral loads and the results obtained are discussed and shown.

\section{Analytical Results}

The static pushover analysis results of the bare frame are regarded as the baseline data for investigating the effect of different infill configurations on the structural behavior of RC frames.

\subsection{The Strength Capacity Investigation:}

The masonry infills have significantly increased the strength capacity of reinforced concrete frames buildings; the load-displacement charts and the percentage of increase are shown in Fig.7, 8, 9.

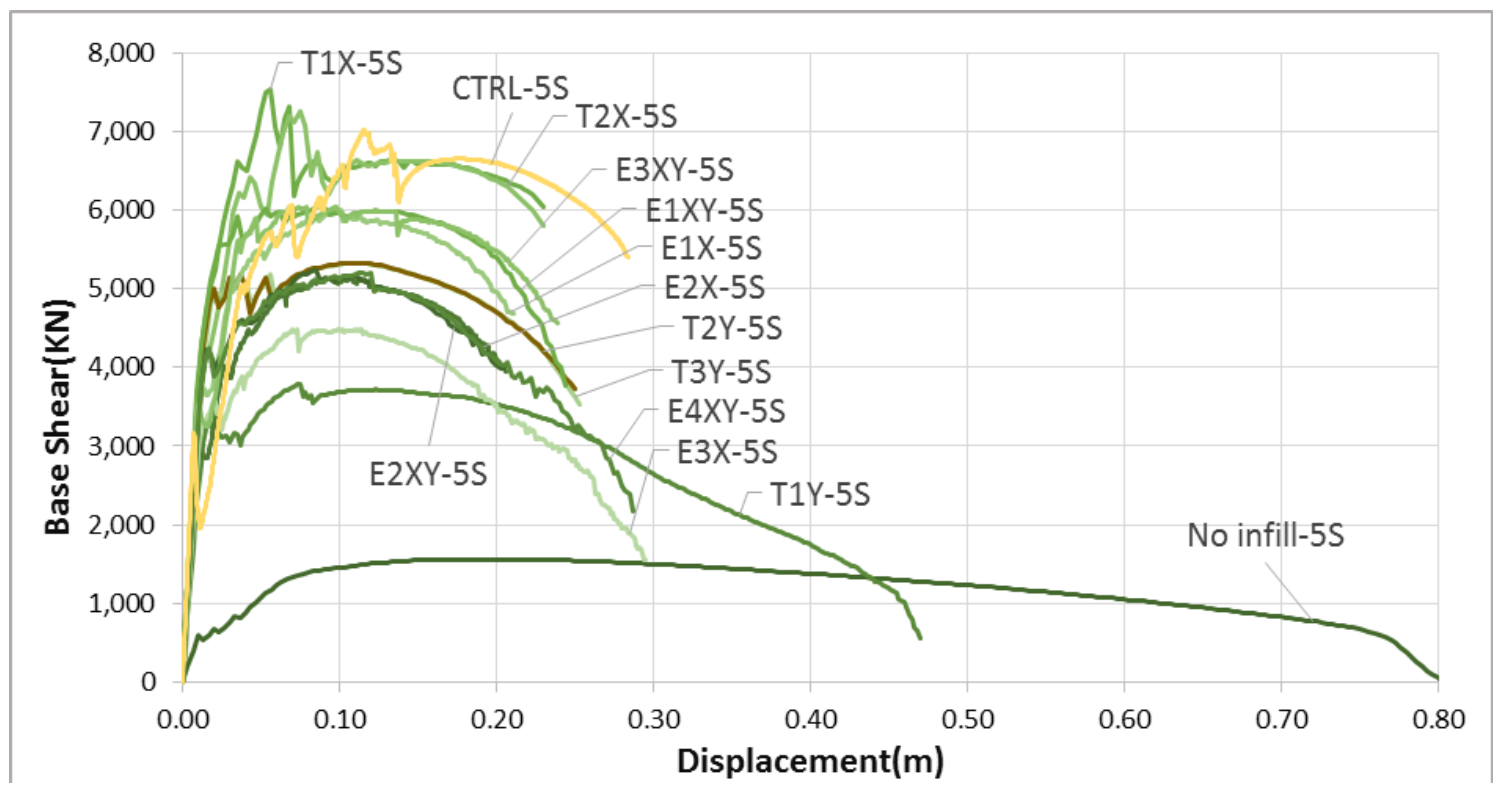

Fig.7 - Comparison between the behavior of bare frame and five-story infilled frames models under incremental static lateral load.

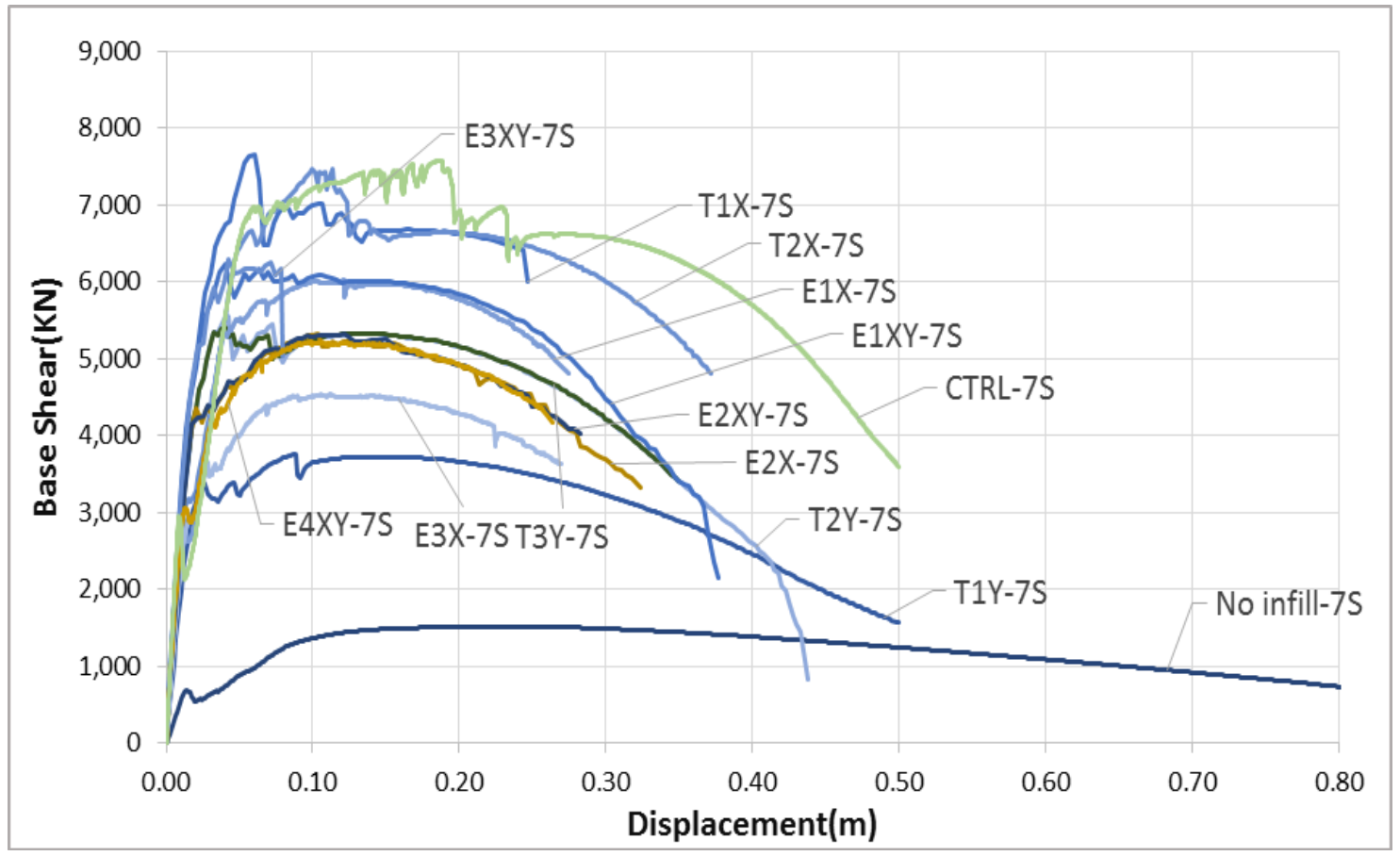

Fig.8-Comparison between the behavior of bare frame and seven-story infilled frames models under incremental static lateral load. 


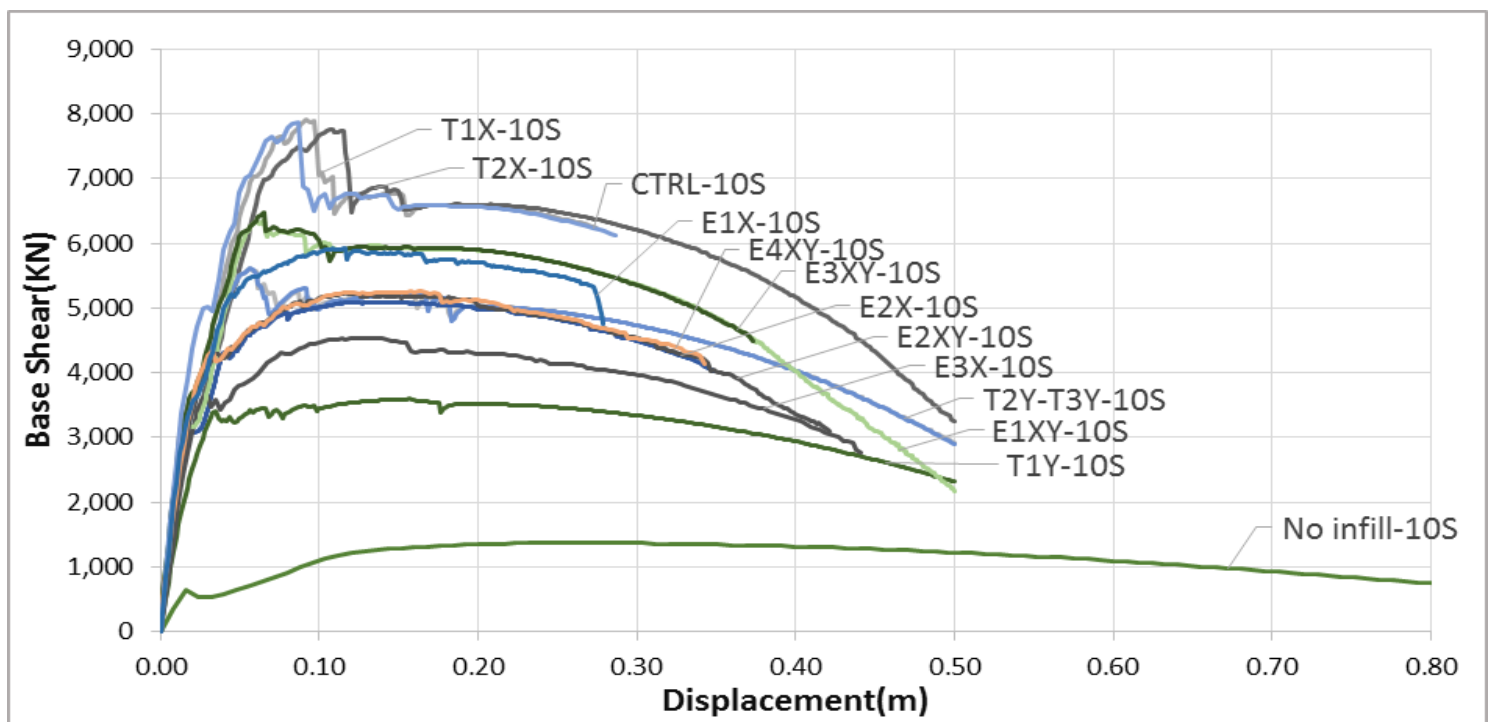

Fig.9 - Comparison between the behavior of bare frame and ten-story infilled frames models under incremental static lateral load.

Table 5. The strength capacity increase of all buildings with respect to the percentage of infills

\begin{tabular}{|l|l|l|l|l|l|l|l|l|l|l|l|l|l|}
\hline Model & T1X & T2X & T1Y & T2Y & T3Y & E1X & E2X & E3X & E1XY & E2XY & E3XY & E4XY & CTRL \\
\hline \%infills $(\mathrm{x})^{1}$ & 84.12 & 84.12 & 33.33 & 58.73 & 58.73 & 71.43 & 58.73 & 46 & 71.43 & 58.73 & 71.43 & 58.73 & 84.12 \\
\hline \%infills(y) & 90 & 70 & 100 & 100 & 100 & 100 & 100 & 100 & 95 & 95 & 85 & 85 & 100 \\
\hline Is \% $-5 S^{3}$ & 482 & 464 & 242 & 340 & 341 & 384 & 329 & 286 & 386 & 335 & 386 & 333 & 448 \\
\hline Is \% $-7 S^{4}$ & 504 & 492 & 248 & 366 & 357 & 397 & 351 & 298 & 411 & 351 & 415 & 384 & 499 \\
\hline Is \% $-10 S^{5}$ & 577 & 565 & 262 & 409 & 410 & 375 & 372 & 331 & 463 & 382 & 473 & 335 & 574 \\
\hline
\end{tabular}

${ }^{1} \%$ infills(x) is the percentage of infills in X-direction (lateral load direction).

$2 \%$ infills(y) is the percentage of infills in Y-direction.

${ }^{3} \mathrm{I}_{\mathrm{s}} \%-5 \mathrm{~S}$ is the percentage of strength capacity increase for 5-story models compared to that of bare frame.

${ }^{4} I_{s} \%-7 S$ is the percentage of strength capacity increase for 7-story models compared to that of bare frame.

${ }^{5} \mathrm{I}_{\mathrm{s}} \%-10 \mathrm{~S}$ is the percentage of strength capacity increase for 10-story models compared to that of bare frame.

From Table 5, the model (T1Y) with the least percentage of infills has the least increase in strength capacity and models with the highest percentage of infills (such as T1X and CTRL) have the highest increase in strength capacity so it can be concluded that the strength capacity of the building is directly proportional to the percentage of infills in the building while the ductility of structure is inversely proportional to the infill ratio of the structure that the bare frame building has the most ductile performance of all structures performances. For the 7-story buildings, the strength capacity has significantly increased than the strength capacity of the 5-story buildings. Also the performance of models is more ductile than that of the 5-story models as some models (CTRL and T1Y) have reached a displacement of $0.5 \mathrm{~m}$ before collapse. For the 10-story buildings, the strength capacity has slightly increased than that of 7-story buildings but the models performance has significantly changed as clearly the ductility increased and most of models reached $0.5 \mathrm{~m}$ displacement or more before collapse.

For each model performance, the first drop in strength for the partially-infilled frame is due to the brittle failure of masonry materials initiating in the first-story infill walls. Lateral loads are subsequently redistributed and the pushover curve reaches its peak strength again as the walls in upper stories and frame elements are subjected to higher loads. This behavior after first-story wall failure is due to wall-frame interaction and depends on the relative strength of the infill and framing.

\subsection{The Response of buildings under Incremental Lateral Load:}

For almost all buildings, the first cracks resulted from lateral loading are detected in the concrete cover of beams in the first stories then the cracks extend to the confined concrete of beams in tension. After cracking of beams, the cracking of columns starts from the concrete cover to the confined concrete in tension. The reinforcement steel starts yielding at the first stories beams then for the whole building. The last cracks happen 
to appear in the confined concrete of columns in compression as shown in figures. Also the models were studied with different number of stories such as 5, 7 and 10 stories and it can be concluded that the overall performance of 7-story buildings is in between the 5-story and 10-story buildings.

The performance criteria of buildings was:

1- Cracking of unconfined concrete of beams in tension (at tensile strain $\varepsilon_{t}=0.0001165$ ).

2- Cracking of confined concrete of beams in tension (at tensile strain $\varepsilon_{t}=0.0001165$ ).

3- Cracking of unconfined concrete of columns in tension (at tensile strain $\varepsilon_{\mathrm{t}}=0.0001165$ ).

4- Cracking of confined concrete of columns in tension (at tensile strain $\varepsilon_{\mathrm{t}}=0.0001165$ ).

5- Yielding of reinforcement steel of beams (at yield strain $\varepsilon_{\mathrm{y}}=0.0018$ ).

6- Reaching the shear capacity of columns $\left(\mathrm{Q}_{\max -5-\text { Story }}=70 \mathrm{kN}, \mathrm{Q}_{\max -5 \text {-Story }}=90 \mathrm{kN}, \mathrm{Q}_{\max -5 \text {-Story }}=120 \mathrm{kN}\right)$.

7- Cracking of unconfined concrete of beams in compression (at compressive strain $\varepsilon_{\mathrm{c}}=-0.0035$ ).

8- Cracking of confined concrete of beams in compression (at compressive strain $\varepsilon_{\mathrm{c}}=-0.0035$ ).

9- Reaching the shear capacity of beams $\left(Q_{\max }=90 \mathrm{kN}\right)$.

10- Yielding of reinforcement steel of columns (at yield strain $\varepsilon_{\mathrm{y}}=0.0018$ ).

11- Cracking of unconfined concrete of columns in compression (at compressive strain $\varepsilon_{\mathrm{c}}=-0.0035$ ).

12- Cracking of confined concrete of columns in compression (at compressive strain $\varepsilon_{\mathrm{c}}=-0.0035$ ).

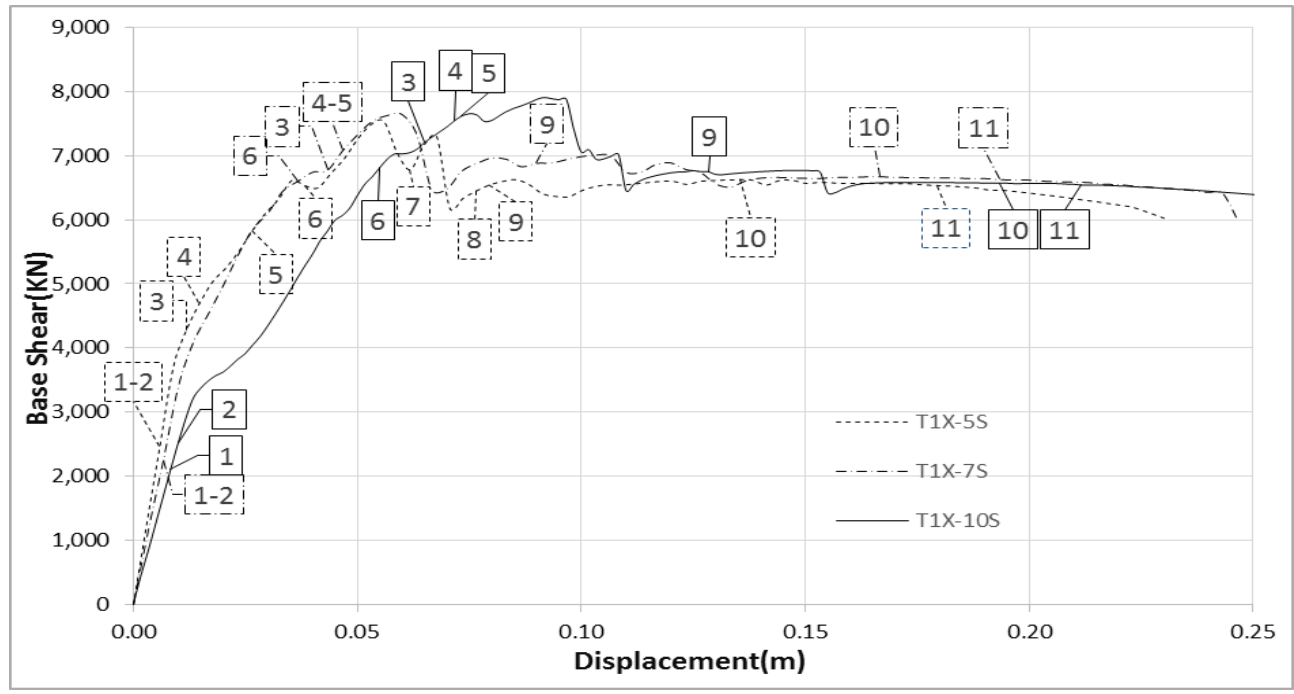

Fig.10 -The performance of T1X buildings for 5, 7, 10 stories.

The performance of any building under lateral loads is widely influenced by the infill ratio, walls configurations, and number of stories of the building. For an infill ratio of $84.12 \%$ in X-direction and $90 \%$ in $\mathrm{Y}$ direction in a symmetrical plan, the first crack in the concrete of columns appears in 5-story buildings at a displacement less than that of 7 -story buildings by $73 \%$ and that of 10 -story buildings by $81.5 \%$ and the reinforcement steel yields in 5-story buildings at a displacement less than that of 7 -story buildings by $43.5 \%$ for beams and $19.7 \%$ for columns., the reinforcement steel yields in 7-story buildings at a displacement less than that of 10 -story buildings by $36 \%$ for beams and $13.8 \%$ for columns. Also the columns reach its maximum shear capacity in 5-story buildings and 7- story buildings at a displacement less than that of 10-story buildings by $29 \%$ as shown in Fig.10. 


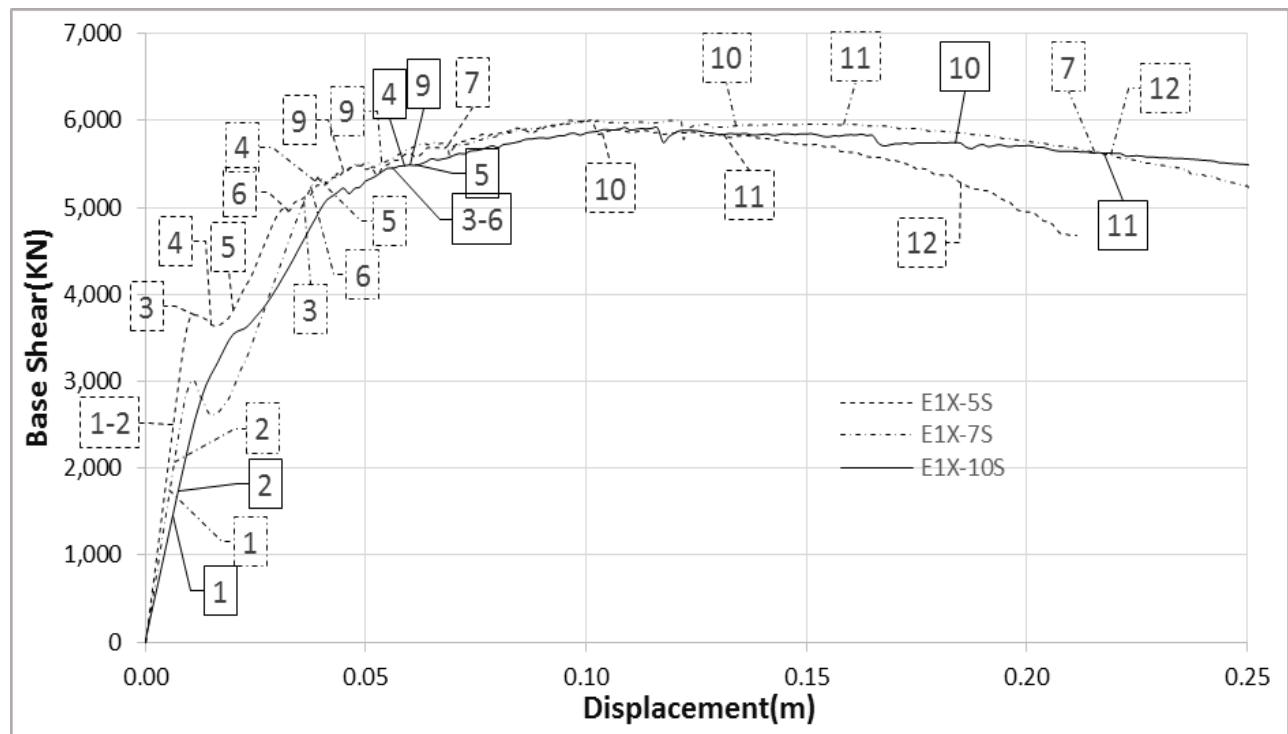

Fig.11 - The performance of E1X buildings for 5, 7, 10 stories.

For an infill ratio of $71.43 \%$ in X-direction and $100 \%$ in Y-direction in an unsymmetrical plan, the first crack in the concrete of columns appears in 5-story buildings at a displacement less than that of 7-story buildings by $68 \%$ and that of 10 -story buildings by $80 \%$ and the reinforcement steel yields in 5 -story buildings at a displacement less than that of 7 -story buildings by $49 \%$ for beams and $23.2 \%$ for columns., the reinforcement steel yields in 7 -story buildings at a displacement less than that of 10 -story buildings by $36.4 \%$ for beams and $26.7 \%$ for columns. Also the columns reach its maximum shear capacity in 5-story buildings at a displacement less than that of 7 - story buildings by $13 \%$ and at a displacement less than that of 10 -story buildings by $45 \%$ as shown in Fig. 11 .

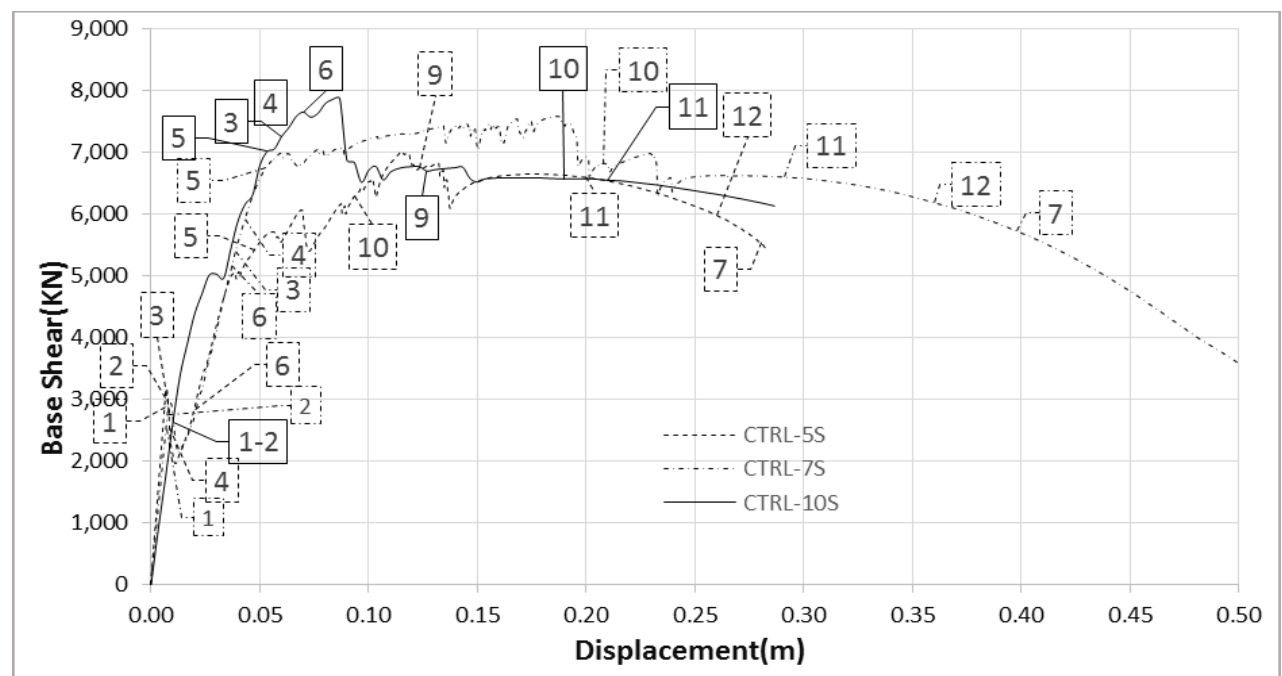

Fig.12 -The performance of CTRL buildings for 5, 7, 10 stories.

For an infill ratio of $84.12 \%$ in $\mathrm{X}$-direction and $100 \%$ in Y-direction in a symmetrical plan, the first crack in the concrete of columns appears in 5-story buildings at a displacement less than that of 7-story buildings by $77.3 \%$ and that of 10 -story buildings by $86.2 \%$ and the reinforcement steel yields in 5 -story buildings at a displacement less than that of 7 -story buildings by $9 \%$ for beams and $56 \%$ for columns., the reinforcement steel yields in 7 -story buildings at a displacement less than that of 10 -story buildings by $5 \%$ for beams and greater than that of 10 -story buildings by $6.5 \%$ for columns. Also the columns reach its maximum shear capacity in 5-story buildings at a displacement less than that of 7 - story buildings by $46 \%$ and at a displacement less than that of 10-story buildings by $72 \%$ as shown in Fig. 12 . 


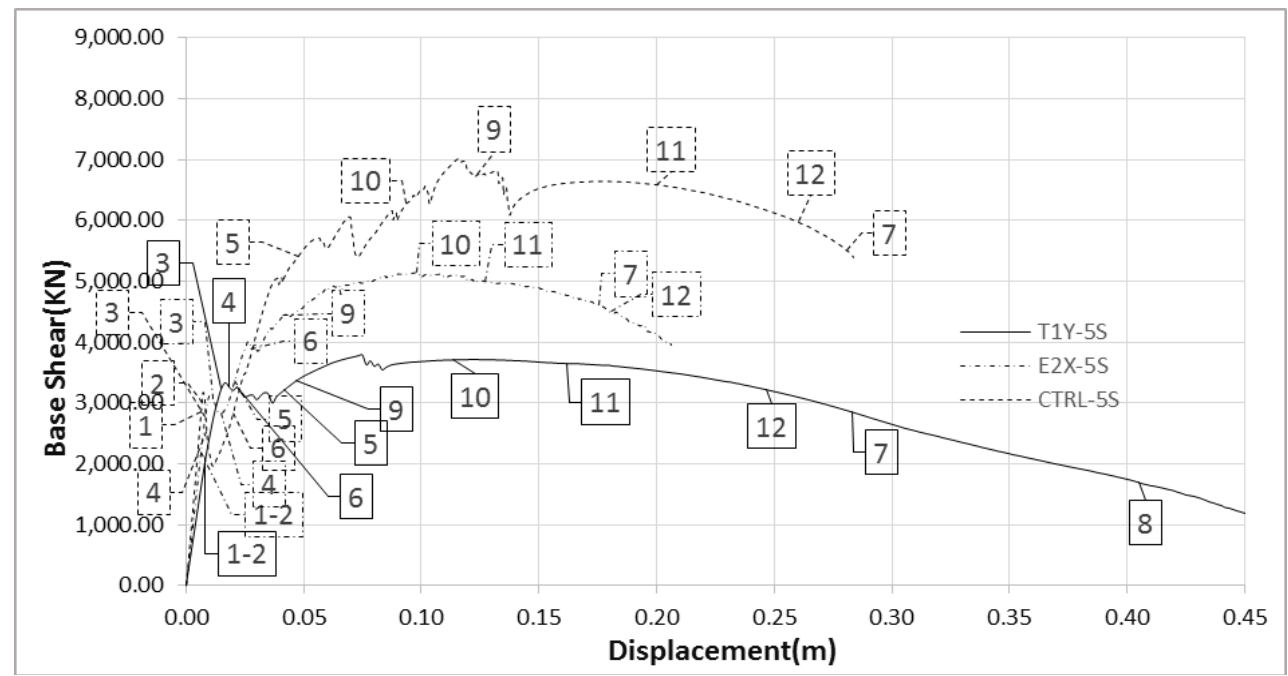

Fig.13 -The performance of models with different infill ratios.

The model T1Y with the least infill ratio has the most ductile performance and the most fragile too as shown in Fig.13; the columns of the building reach its maximum shear capacity in T1Y model at a displacement of $0.046 \mathrm{~m}$ while in the model CTRL with the highest infill ratio, the columns reach its maximum shear capacity at a displacement of $0.12 \mathrm{~m}$. The first crack in the concrete of beams appears at a displacement of $0.0063 \mathrm{~m}$ for CTRL and E2X models and at a displacement of $0.0083 \mathrm{~m}$ for T1Y model also the reinforcement steel of columns yields in CTRL model at a displacement of $0.093 \mathrm{~m}$, at a displacement of $0.099 \mathrm{~m}$ in E2X model and at a displacement of $0.13 \mathrm{~m}$ in T1Y model; therefore the ductility of the structure is inversely proportional to the infill ratio in the structure and the increase of infill ratio increase the brittleness of the structure

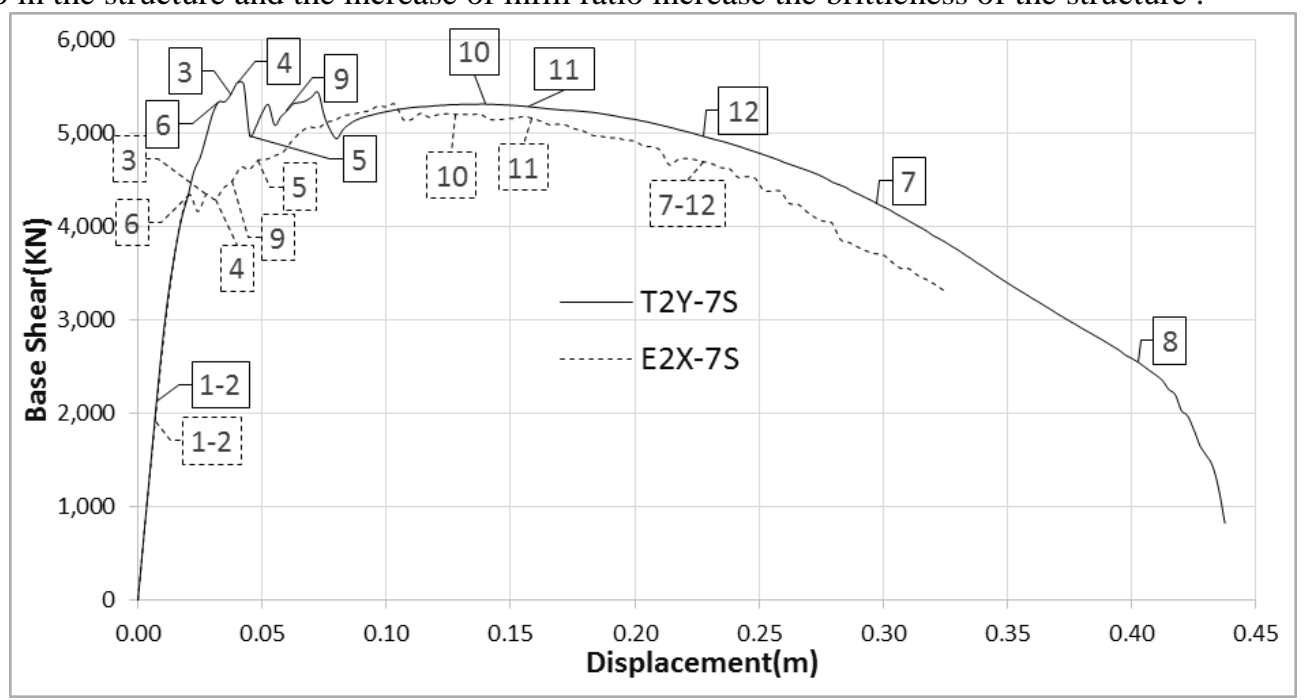

Fig.14 -The performance of models with the same infill ratios but different wall distribution.

The model T2Y has a symmetrical plan while the model E2X has an unsymmetrical plan. As shown in Fig.14, in model T2Y the unconfined and confined concrete of beams and columns cracks at a greater displacement than that of model E2X by a factor of 1.087; also the reinforcement steel of columns yields in model T2Y at a displacement greater than that of the model E2X by a factor of 1.093; the beams and the columns of model T2Y reach their maximum shear capacity at a displacement greater than that of model E2X by a factor 1.58 and 1.625 respectively. So it can be concluded that the symmetry in walls distribution throughout the plan increases the strength and the ductility of the building when subjected to lateral loads.

\subsection{Identification of Response Modification Factor:}

The displacement ductility factor $R_{\mu}$ (Comite Euro-International Du Beton, 1996) is defined by the ratio between failure displacements to yield displacement. Where, the yield displacement $\left(\Delta_{y}\right)$ is the lateral displacements at $80 \%$ from ultimate load at ascending part of curve while the failure displacement $\left(\Delta_{\mathrm{f}}\right)$ is lateral displacement at $80 \%$ from ultimate load at descending part of the curve. The ductility factor is computed using 
Eq.(4) [10].

Ductility factor $\left(R_{\mu}\right)=\frac{\Delta_{f}}{\Delta_{y}}$

Where:

$\Delta_{\mathrm{f}}$ : the failure displacement,

$\Delta_{\mathrm{y}}:$ the yield displacement.

The percentage of infills in Y-direction is defined by the ratio between the total lengths of infills in Ydirection to the total lengths of frames in the same direction while the percentage of infills in $\mathrm{X}$-direction is defined by the ratio between the total lengths of infills in X-direction to the total lengths of frames in the same direction. The maximum global drift is defined by the ratio between the maximum roof drift displacement to the total height of the building and its values are shown in Table 6.

Table 6. Resulted global drift and ductility from static pushover analysis for all models

\begin{tabular}{|c|c|c|c|c|c|}
\hline $\begin{array}{l}\text { No. } \\
\text { of stories }\end{array}$ & MODELS & $\%$ of infills $(\mathbf{Y})^{*}$ & $\%$ of infills $(X)^{* *}$ & $\begin{array}{l}\text { Max. Global } \\
\text { Drift \%*** }\end{array}$ & Ductility \\
\hline \multirow{14}{*}{ 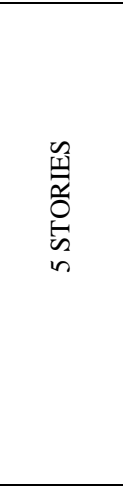 } & NO INFILL & 0 & 0 & 5.4 & 7.89 \\
\hline & CTRL & 100 & 84.127 & 1.893 & 5.37 \\
\hline & $\mathrm{T} 1 \mathrm{X}$ & 90 & 84.127 & 1.53 & 7.93 \\
\hline & $\mathrm{T} 2 \mathrm{X}$ & 70 & 84.127 & 1.53 & 7.18 \\
\hline & $\mathrm{T} 1 \mathrm{Y}$ & 100 & 33.33 & 3.13 & 19.92 \\
\hline & $\mathrm{T} 2 \mathrm{Y}$ & 100 & 58.73 & 1.68 & 16.24 \\
\hline & T3Y & 100 & 58.73 & 1.67 & 17.45 \\
\hline & E1X & 100 & 71.43 & 1.4 & 7.16 \\
\hline & $\mathrm{E} 2 \mathrm{X}$ & 100 & 58.73 & 1.37 & 7.69 \\
\hline & $\mathrm{E} 3 \mathrm{X}$ & 100 & 46 & 1.96 & 9.72 \\
\hline & E1XY & 95 & 71.43 & 1.63 & 14.66 \\
\hline & E2XY & 95 & 58.73 & 1.37 & 11.17 \\
\hline & E3XY & 85 & 71.43 & 1.59 & 7.74 \\
\hline & E4XY & 85 & 58.73 & 1.91 & 13.06 \\
\hline \multirow{14}{*}{ 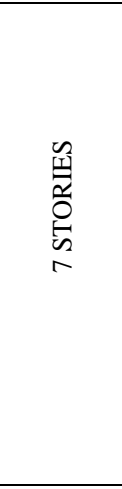 } & NO INFILL & 0 & 0 & 4.7 & 6.62 \\
\hline & CTRL & 100 & 84.127 & 2.38 & 8.31 \\
\hline & $\mathrm{T} 1 \mathrm{X}$ & 90 & 84.127 & 1.43 & 8.13 \\
\hline & $\mathrm{T} 2 \mathrm{X}$ & 70 & 84.127 & 1.75 & 6.98 \\
\hline & $\mathrm{T} 1 \mathrm{Y}$ & 100 & 33.33 & 2.37 & 18.21 \\
\hline & $\mathrm{T} 2 \mathrm{Y}$ & 100 & 58.73 & 2.07 & 13.52 \\
\hline & T3Y & 100 & 58.73 & 1.66 & 14.65 \\
\hline & E1X & 100 & 71.43 & 1.3 & 8.08 \\
\hline & $\mathrm{E} 2 \mathrm{X}$ & 100 & 58.73 & 1.54 & 13.1 \\
\hline & E3X & 100 & 46 & 1.283 & 10.71 \\
\hline & E1XY & 95 & 71.43 & 1.79 & 13.19 \\
\hline & E2XY & 95 & 58.73 & 1.34 & 10.56 \\
\hline & E3XY & 85 & 71.43 & 2.38 & 3.73 \\
\hline & E4XY & 85 & 58.73 & 1.63 & 8.65 \\
\hline \multirow{14}{*}{ 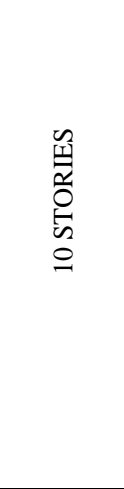 } & NO INFILL & 0 & 0 & 4 & 6.09 \\
\hline & CTRL & 100 & 84.127 & 0.955 & 5.72 \\
\hline & $\mathrm{T} 1 \mathrm{X}$ & 90 & 84.127 & 0.916 & 5.24 \\
\hline & $\mathrm{T} 2 \mathrm{X}$ & 70 & 84.127 & 1.96 & 5.88 \\
\hline & T1Y & 100 & 33.33 & 3.23 & 17.15 \\
\hline & $\mathrm{T} 2 \mathrm{Y}$ & 100 & 58.73 & 2.583 & 11.36 \\
\hline & T3Y & 100 & 58.73 & 2.167 & 11.72 \\
\hline & E1X & 100 & 71.43 & 1.196 & 7.56 \\
\hline & $\mathrm{E} 2 \mathrm{X}$ & 100 & 58.73 & 1.163 & 9.43 \\
\hline & $\mathrm{E} 3 \mathrm{X}$ & 100 & 46 & 1.471 & 12.2 \\
\hline & E1XY & 95 & 71.43 & 1.667 & 7.96 \\
\hline & E2XY & 95 & 58.73 & 1.4 & 10.82 \\
\hline & E3XY & 85 & 71.43 & 1.244 & 8.2 \\
\hline & E4XY & 85 & 58.73 & 1.14 & 11.75 \\
\hline
\end{tabular}

$* \%$ of infills $(\mathrm{Y})=\frac{\sum \mathrm{L} \text { (infills) }}{\sum \mathrm{L} \text { (frames) }} \quad * * \%$ of infills $(\mathrm{X})=\frac{\sum \mathrm{L} \text { (infills) }}{\sum \mathrm{L} \text { (frames) }}$

$* * *$ Max. global drift $\%=\frac{\Delta \max }{\mathrm{H}}$ 

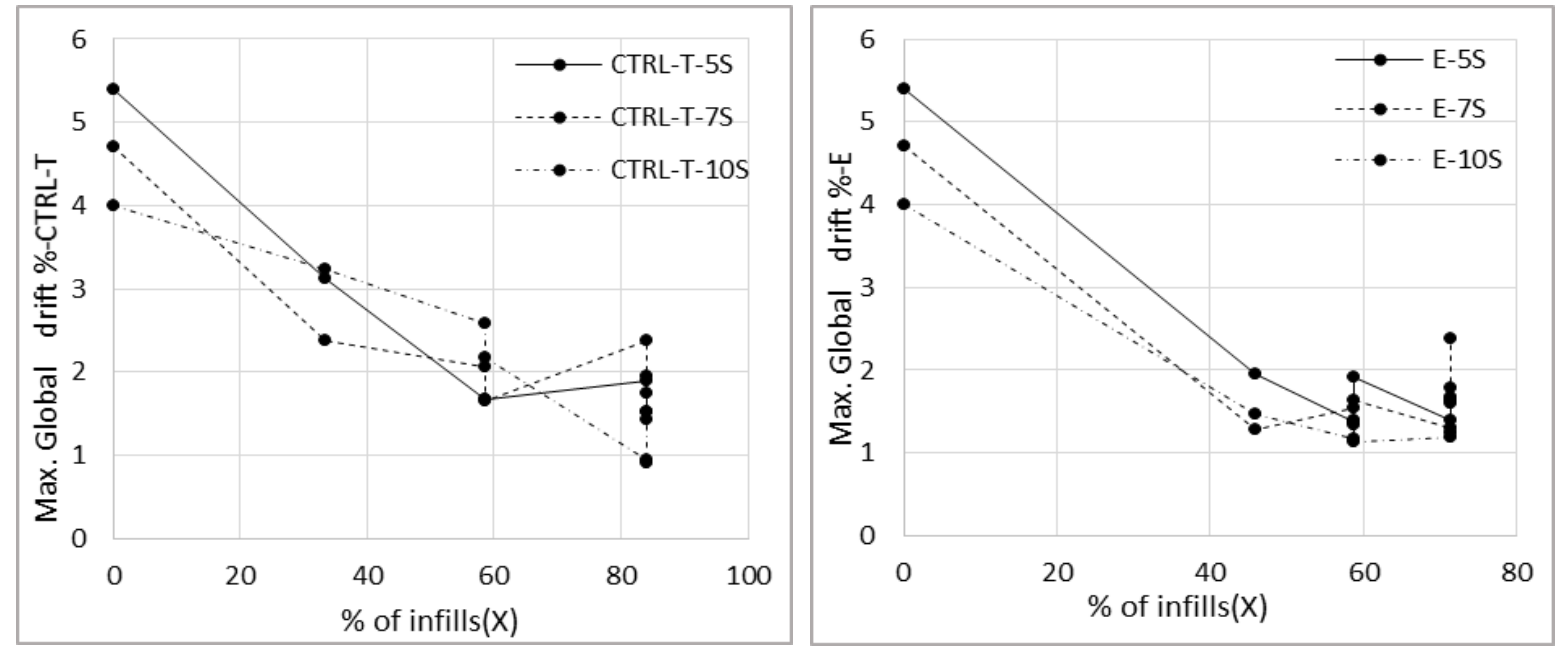

Fig.15 - The effect of infill ratio on the global drift of the control, translational and torsional mode (symmetrical and asymmetrical wall distribution in plan) buildings

For 5-story buildings with regular wall distribution, the percentage of global drift decreases by $43 \%$ when the infill ratio increases by $33.33 \%$ while decreases by $69 \%$ when the infill ratio increases by $58.73 \%$; with irregular wall distribution, the percentage of global drift decreases by $75 \%$ when the infill ratio increases by $58.73 \%$. For 7 -story buildings with regular wall distribution, the percentage of global drift decreases by $56 \%$ when the infill ratio increases by $58.73 \%$ while for irregular wall distribution buildings, the percentage of global drift decreases by $67 \%$ when the infill ratio increases by $58.73 \%$. And for 10 -story buildings with regular wall distribution, the percentage of global drift decreases by $37.5 \%$ when the infill ratio increases by $58.73 \%$ while for irregular wall distribution buildings, the percentage of global drift decreases by $71 \%$ when the infill ratio increases by $58.73 \%$. So it can be conclude that the top drift of buildings subjected to lateral loads decreases with the increase of infill ratio and the number of stories as shown in Fig.15.
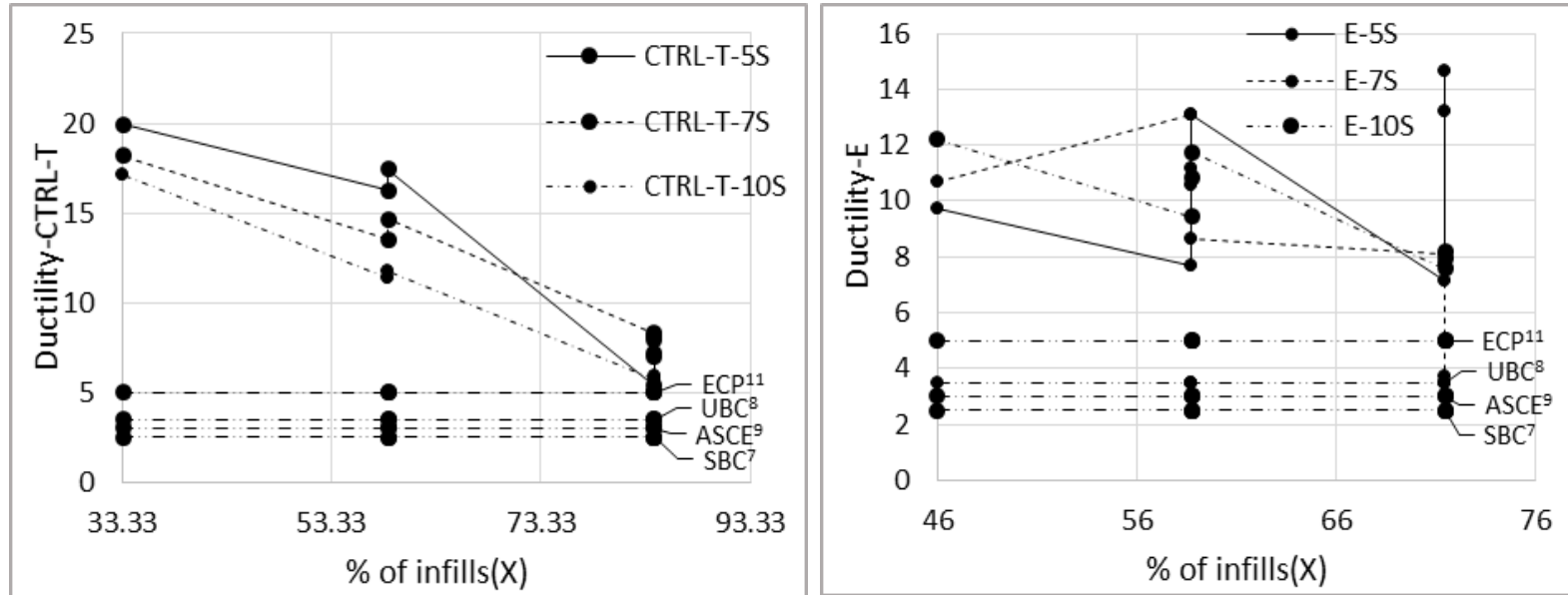

Fig.16 - The effect of infill ratio on the ductility of the control, translational and torsional mode (symmetrical and asymmetrical wall distribution in plan) buildings compared with ductility values in different codes.

The ductility factor varies with respect to the percentage of infills and the wall configurations in each building (see Table 6), so it's not accurate to specify a certain value for each system. Whereas for 5-story buildings with regular wall distribution, the ductility factor decreases by $18.5 \%$ with the increase of infill ratio by $25.4 \%$ and decreases by $84 \%$ with the increase of infill ratio by $50.79 \%$ while for 7 -story buildings with regular wall distribution, the ductility factor decreases by $26 \%$ with the increase of infill ratio by $25.4 \%$ and decreases by $55 \%$ with the increase of infill ratio by $50.79 \%$ and for 10 -story buildings with regular wall distribution, the ductility factor decreases by $34 \%$ with the increase of infill ratio by $25.4 \%$ and decreases by $67 \%$ with the increase of infill ratio by $50.79 \%$. But for 5 -story buildings with irregular wall distribution, the ductility factor decreases by $20.89 \%$ with the increase of infill ratio by $12.73 \%$ and decreases by $27.4 \%$ with the increase of infill ratio by $25.43 \%$ while for 10 -story buildings with irregular wall distribution, the ductility factor decreases by $23 \%$ with the increase of infill ratio by $12.73 \%$ and decreases by $38 \%$ with the increase of infill 
ratio by $25.43 \%$. From Fig.16, it can be concluded that the similarity in wall distribution throughout the story increases the ductility factor by approximately by $100 \%$ that the torsional effect cause excessive ductility demands on the structure also the ductility factor decreases in higher structures.

\section{Conclusion}

This paper presented an analytical investigation in the seismic response of infilled-frame buildings. A number of prototypical building structures were analyzed using different number of stories and infill distribution patterns. The key finding of this investigation may be summarized as follows:

1- Nonlinear push-over analysis showed that the lateral strength and stiffness of the structure with infill walls increased significantly due to the contribution of the infill walls, which are generally neglected due to their tendency to premature strength loss during seismic events. Capacity increase reached values as high as 482 $\%, 504 \%, 577 \%$ compared to the bare frames for five, seven and ten stories building, respectively.

2- Ductility factors of structures, expressed as the maximum deformation divided by the corresponding yield deformation, are useful non-dimensional indices of inelastic deformations. However using fixed values for these factors across all the similar type of structures was shown to be unreasonable, and may yield overly conservative designs for the ductile building structures.

3- Analytical results demonstrated that as the percentage of the infills increases, the corresponding response modification factor decreases. A similar inverse proportionality relationship also holds for the building drift under lateral loads. This is attributed to the added stiffness contribution of the infill walls to the bare frames.

4- Although this study did not cover all possible factors affecting the seismic response of infilled frame buildings, it is clear that the response modification factors presented in national and international codes needs revisiting. The margin of overestimation of the seismic forces is considered large given the inherent strength and ductility of the system. This shall lead to more efficient and economic designs if the response modification factors are related to infill percentages and distributions.

\section{References}

[1]. Applied technology council and Federal emergency management agency, FEMA P695 Quantification of Building Seismic Performance Factors, June 2009.

[2]. CVR Murty and Sudhir K Jain, "Beneficial influence of masonry infill walls on seismic performance of RC frame buildings", 12WCEE 2000.

[3]. Ivo Caliò and Bartolomeo Pantò, "A macro-element modelling approach of Infilled Frame Structures", Computers and Structures 143 (2014) 91-107.

[4]. A. Kadida, S. Nouia, A. Zinea and D. Yahiaouib, "Behavior of Reinforced Concrete Infilled Frames under Seismic Loads", CherSiang Tan et al. / Jurnal Teknologi (Sciences \& Engineering) 61:3 (2013).

[5]. Polyakov SV, "The interaction between masonry filler walls and enclosing frame when loading in the plane of the wall", Earthquake Engineering Research Institute; 1960.

[6]. Holmes M., "Steel frame with brickwork and concrete infilling", Inst Technol, Bradford 1961.

[7]. Standard building code SBC 301, 2007.

[8]. Uniform Building Code UBC-volume 2, 1997.

[9]. American Society of Civil Engineering ASCE 7-05, 2005.

[10]. Ahmed Sayed, Ahmed Tawfik Essa, Mohamed Ragai Kotp Badr and Ashraf Hasan El-Zanaty, "Effect of infill wall on the ductility and behavior of high strength reinforced concrete frames", HBRC Journal (2014) 10, 258-264.

[11]. Egyptian code of practice of reinforced concrete ECP 203; 2007

[12]. SeismoStruct v6.0 - "A computer program for static and dynamic nonlinear analysis of framed structures" Seismosoft [2012]. 